Tropical Journal of Pharmaceutical Research February 2019; 18 (2): 403-408

ISSN: $1596-5996$ (print); 1596-9827 (electronic)

(C) Pharmacotherapy Group, Faculty of Pharmacy, University of Benin, Benin City, 300001 Nigeria.

\title{
Effects of concurrent treatment with amitriptyline hydrochloride tablets and fluoxetine hydrochloride on therapeutic indicator levels in patients with depression
}

\author{
Yin Jie ${ }^{1 *}$, Deng Shuang ${ }^{2}$, Zhan Xinjie ${ }^{3}$ \\ ${ }^{1}$ Department of Psychology, Nanjing Institute of Politics, Nanjing City, ${ }^{2}$ College of Life Sciences, Hunan University of Science \\ and Technology, Xiangtan City, ${ }^{3}$ Department of Clinical Laboratory, Ningxiang People's Hospital, Ningxiang City, China
}

*For correspondence: Email: rj1187@163.com

Sent for review: 2 November 2018

Revised accepted: 17 January 2019

\begin{abstract}
Purpose: To investigate the effects of combined treatment of amitriptyline hydrochloride tablets and fluoxetine hydrochloride on therapeutic indicator levels in depressive patients.

Methods: Patients with depression $(n=104)$ were divided into control group and study group (52 cases each) using random number table method. Control group was treated with oral fluoxetine hydrochloride (FH) tablets only, while the study group received amitriptyline hydrochloride tablets, in addition to fluoxetine hydrochloride tablets. Both treatments lasted 3 months. Clinical effects and thyroid function indices were determined and compared for the two groups.

Results: Treatment effectiveness in the study group (92.3\%) was markedly higher than that in control group $(75.0 \%, p<0.05)$. In both groups, Pittsburgh Sleep Quality Index, Hamilton Depression Scale and Hamilton Anxiety Table scores significantly decreased post-treatment $(p<0.05)$. In contrast, there was significant increase in $\mathrm{Y}$-aminobutyric acid (GABA) and serotonin (5-HT) levels in the two groups. In both groups, T3 and T4 significantly decreased while thyroid stimulating hormone (TSH) increased significantly $(p<0.05)$. Thyroid function in the study group was markedly higher than in the control group $(p<0.05)$.

Conclusion: Combination treatment with amitriptyline hydrochloride tablets and FH is more effective than FH alone in the treatment of patients with depression. The combined treatment has a high degree of safety and is recommended for clinical application.
\end{abstract}

Keywords: Amitriptyline hydrochloride, Fluoxetine hydrochloride, Depression, PSQI score, HAMD-17 score, HAMA score, GABA, 5-HT

This is an Open Access article that uses a funding model which does not charge readers or their institutions for access and distributed under the terms of the Creative Commons Attribution License (http://creativecommons.org/licenses/by/4.0) and the Budapest Open Access Initiative (http://www.budapestopenaccessinitiative.org/read), which permit unrestricted use, distribution, and reproduction in any medium, provided the original work is properly credited.

Tropical Journal of Pharmaceutical Research is indexed by Science Citation Index (SciSearch), Scopus, International Pharmaceutical Abstract, Chemical Abstracts, Embase, Index Copernicus, EBSCO, African Index Medicus, JournalSeek, Journal Citation Reports/Science Edition, Directory of Open Access Journals (DOAJ), African Journal Online, Bioline International, Open-J-Gate and Pharmacy Abstracts

\section{INTRODUCTION}

The main clinical feature of mood disorder is persistent depression. In the affected patients, depression can range from melancholy to grief or even suicidal behavior, which seriously endangers physical and mental health [1]. Currently, drugs are the main treatment strategy for depression above moderate level. The popular therapeutic drugs are the traditional tricyclic and four-ring anti-depressants, but these 
are associated with numerous adverse reactions which many patients are unable to tolerate $[2,3]$.

With increasing incidence, depression has become one of the key research issues in the medical field in recent years. Studies suggest that although amitriptyline hydrochloride has high clinical effectiveness, it is linked with cardiotoxicity and poor patient compliance. Fluoxetine hydrochloride has high selectivity and weak antidepressant effect, with low side effects. The combination of these two drugs can strengthen the outcome of depression treatment and reduce the occurrence of adverse reactions $[4,5]$.

Therefore, in the present study, a combination of amitriptyline hydrochloride tablets and fluoxetine hydrochloride was used to treat patients with depression, and the effect of the treatments on PSQI, HAMD-17, HAMA score, GABA and 5-HT levels of the patients were determined.

\section{EXPERIMENTAL}

\section{General information}

A total of 104 depressive illness patients were selected for treatment from January 2016 to January 2017. The study received approval from the Ethical Committee of Department of Psychology, Nanjing Institute of Politics (approval no. 201810573), and was carried out in line with the guidelines of Helsinki Declaration of 1964 as amended in 1996 [6].

\section{Inclusion criteria}

All the inclusion criteria for depression were in line with the "Chinese Mental Disorders Classification and Diagnostic Criteria, 3rd Edition" diagnostic criteria for depression i.e. PSQI score > 5 points, HAMD-17 score > 18 points, and HAMA score $<21$ points. In addition, patients aged 18 to 60 years, and who signed informed consent form with their family members were included.

\section{Exclusion criteria}

Patients with severe cerebral disease and severe heart, liver, kidney and other physical diseases; patients allergic to amitriptyline and fluoxetine tablets, and patients with severe depression and suicidal tendency were excluded from the study. In addition, patients who abused alcohol or drugs, pregnant and lactating patients, and those who did not follow doctor's advice on taking their medication timely, were excluded. There were 44 men and 60 women, aged 18 - 60 years (mean age $=37.2 \pm 11.46$ years), with disease course of 6 - 36 months. The patients were assigned (without bias) to control and study groups (52 patients each). As shown in Table 1, age, sex, and duration of disease were similar in both groups $(p>0.05)$.

\section{Treatments}

The control group was treated with oral fluoxetine hydrochloride at an initial dose of $20 \mathrm{mg}$ at a time, once a day in the morning, and the amount was increased appropriately according to changes in disease situation, but not exceeding $60 \mathrm{mg} /$ day. The study group took amitriptyline hydrochloride tablets, in addition to fluoxetine. The initial fluoxetine dose was $75 \mathrm{mg}$ twice a day. Both groups were treated continuously for 3 months.

\section{Therapeutic indicators}

\section{Clinical effectiveness}

The difference between the HAMD score after treatment and the pre-treatment score was calculated. Healing was indicated by HAMD reduction $\geq 75 \%$ and disappearance of clinical symptoms. Significant improvement was indicated by HAMD reduction $\geq 50 \%$, significant disappearance of clinical symptoms or their significant reduction. Treatment was deemed effective with HAMD reduction $\geq 30 \%$, and reduced clinical symptoms. Treatment was invalid if $\mathrm{HAMD}$ reduction $<30 \%$, and if clinical symptoms were not alleviated. Total effectiveness $(\mathrm{Te})$ was calculated as shown in Eq $1[7]$.

$\mathrm{Te}=\{(\mathrm{h}+\mathrm{s}+\mathrm{e}) / \mathrm{T}\}$

where $\mathrm{h}$ is the no. of healed cases, $s$ is significant cases, $e$ is effective cases and $T$ is total number of cases.

Table 1: Profile of the patients

\begin{tabular}{|c|c|c|c|c|c|}
\hline Group & Gender (n) & $\begin{array}{l}\text { Age range } \\
\text { (years) }\end{array}$ & $\begin{array}{l}\text { Mean age } \\
\text { (years) }\end{array}$ & Duration (months) & $\begin{array}{c}\text { Mean disease duration } \\
\text { (months) }\end{array}$ \\
\hline Control & $\begin{array}{l}\text { Male (24) } \\
\text { Female (28) }\end{array}$ & $23-48$ & $34.28 \pm 3.49$ & $6-36$ & $18.32 \pm 3.47$ \\
\hline Study & $\begin{array}{l}\text { Male (20) } \\
\text { Female (32) }\end{array}$ & $22-49$ & $35.14 \pm 4.18$ & $7-38$ & $19.14 \pm 3.53$ \\
\hline
\end{tabular}


Before and after treatment, the scores of PSQI, HAMD-17 and HAMA were measured through questionnaire. Higher PSQI scores were associated with worse quality of sleep. In the HAMA scale, a HAMA score $<8$ points is normal; 8 - 20 points indicate likelihood of depression; 20 to 35 confirm depression; $>35$ points indicate severe depression; $\geq 7$ points show anxiety, $\geq 14$ points confirm anxiety, $\geq 21$ points indicate significant anxiety, and $\geq 29$ points show severe anxiety. Venous blood was taken from all patients before and after treatment. $Y$ Aminobutyric acid (GABA), serotonin (5-HT) and thyroid function (T3, T4 and TSH) levels were determined using ELISA.

\section{Assessment of adverse reactions}

Incidence of clinical adverse reactions was assessed according to the side effects scale (TESS).

\section{Statistical analysis}

Numeric data are presented as mean $\pm S D$, and were compared using parallel $t$-test. Counting data are expressed as percentage, and were compared using parallel $X^{2}$ test. All statistical analyses were done using SPSS 19.0 mathematical statistics software. Values of $p<$ 0.05 were assumed to indicate statistical significance.

\section{RESULTS}

\section{Treatment effectiveness}

After treatment, total effectiveness in the study group $(92.3 \%)$ was markedly higher than that of control $(75.0 \%, p<0.05)$.

\section{PSQI, HAMD-17 and HAMA scores}

As shown in Table 3, pre-treatment scores in PSQI, HAMD-17, and HAMA were similar in the two groups $(p>0.05)$. However, post-treatment PSQI, HAMD-17, and HAMA scores were significantly lowered in the two groups, but the degree of reduction in the study group was statistically less than the corresponding control value $(p<0.05)$.
Table 3: PSQI, HAMD-17 and HAMA scores (mean \pm $\mathrm{SD}, \mathrm{N}=32$ )

\begin{tabular}{lcccc}
\hline Group & Time & $\begin{array}{c}\text { PSQI } \\
\text { score } \\
\text { (min) }\end{array}$ & $\begin{array}{c}\text { HAMD- } \\
\text { 17 score } \\
\text { (min) }\end{array}$ & $\begin{array}{c}\text { HAMA } \\
\text { score } \\
\text { (min) }\end{array}$ \\
\hline \multirow{2}{*}{ Control } & Pre- & 12.70 & $25.03 \pm$ & $14.04 \pm$ \\
& treatment & \pm 2.87 & 3.35 & 3.02 \\
& Post- & $8.24 \pm$ & $14.63 \pm$ & $8.01 \pm$ \\
& treatment & $2.57^{*}$ & $3.91^{*}$ & $2.48^{*}$ \\
& Pre- & 12.94 & $25.97 \pm$ & $15.00 \pm$ \\
Study & treatment & \pm 2.32 & 3.75 & 3.69 \\
& Post- & $7.50 \pm$ & $11.79 \pm$ & $7.49 \pm$ \\
& treatment & $2.15^{\star} \Delta$ & $3.14^{\star} \Delta$ & $2.22^{*} \Delta$ \\
\hline
\end{tabular}

${ }^{*} P<0.05$, relative to pre-treatment in the same group; $\Delta p<0.05$, relative to control post-treatment

\section{Biochemical indices (GABA and 5-HT)}

Table 4 shows that pre-treatment values of serum GABA and 5-HT were comparable in both groups $(p>0.05)$. However, post-treatment serum GABA and 5-HT were significantly increased in both groups, relative to their levels before treatment, but the increases in the study group patients were markedly higher than control values $(p<0.05)$.

Table 4: Serum biochemical indices (GABA and 5-HT, mean \pm SD)

\begin{tabular}{lccc}
\hline Group & Time & $\begin{array}{c}\text { GABA } \\
(\mathbf{m g} / \mathbf{g})\end{array}$ & $\begin{array}{c}5-H T \\
(\boldsymbol{\mu g} / \mathbf{L})\end{array}$ \\
\hline \multirow{4}{*}{ Control } & Before & $73.92 \pm$ & $108.41 \pm$ \\
& treatment & 22.44 & 31.72 \\
& After & $82.46 \pm$ & $115.34 \pm$ \\
& treatment & $16.18^{\star}$ & $16.51^{*}$ \\
& Before & $73.33 \pm$ & $108.32 \pm$ \\
Study & treatment & 21.61 & 31.84 \\
& After & $89.12 \pm$ & $122.37 \pm$ \\
& treatment & $15.11^{*} \Delta$ & $19.74^{\star} \Delta$ \\
\hline
\end{tabular}

${ }^{\star} P<0.05$, relative to pre-treatment in the same group; $\Delta p<0.05$, relative to control post-treatment

\section{Thyroid function}

Table 5 shows that after three months of treatment, the levels of T3 and T4 in the two groups were significantly decreased, while TSH level was significantly increased $(p<0.05)$. However, the improvement in thyroid function in the study group patients was superior to that of control patients $(p<0.05)$.

Table 2: Clinical effectiveness in the two groups (\%, $n=52)$

\begin{tabular}{lccccc}
\hline Group & Healed & $\begin{array}{c}\text { Significantly } \\
\text { improved }\end{array}$ & Effective & Ineffective & $\begin{array}{c}\text { Total effectiveness } \\
(\%)\end{array}$ \\
\hline Study & 21 & 15 & 12 & 4 & 92.30 \\
Control & 13 & 16 & 10 & 13 & 75.00 \\
\hline
\end{tabular}


Table 5: Thyroid function (mean $\pm \mathrm{SD}, \mathrm{N}=32$ )

\begin{tabular}{lcccc}
\hline Group & Time & $\begin{array}{c}\text { T3 } \\
(\mathbf{p m o l} / \mathrm{L})\end{array}$ & $\begin{array}{c}\text { T4 } \\
(\mathbf{p m o l} / \mathrm{L})\end{array}$ & $\begin{array}{c}\text { TSH } \\
(\mu \mathrm{U} / \mathrm{L})\end{array}$ \\
\hline \multirow{4}{*}{ Control } & Before & $4.84 \pm$ & $17.67 \pm$ & $1.23 \pm$ \\
& treatment & 0.97 & 1.03 & 0.57 \\
& After & $3.92 \pm$ & $15.20 \pm$ & $1.44 \pm$ \\
& treatment & $0.70^{*}$ & $0.95^{*}$ & $0.34^{*}$ \\
& Before & $4.84 \pm$ & $17.69 \pm$ & $1.22 \pm$ \\
Study & treatment & 0.94 & 1.31 & 0.39 \\
& After & $2.82 \pm$ & $13.24 \pm$ & $1.87 \pm$ \\
& treatment $\Delta$ & $0.48^{*} \Delta$ & $0.81^{*} \Delta$ & $0.22^{*} \Delta$ \\
\hline
\end{tabular}

${ }^{\star} P<0.05$, relative to pre-treatment in the same group; $\Delta p<0.05$, relative to control post-treatment

\section{Adverse reactions}

Table 6 shows that the main adverse reactions in the two groups were dry mouth, lethargy, nausea and loss of appetite. The study group patients had a slight edge over patients in control group, with respect to incidence of adverse reactions. However, after symptomatic treatment, they were relieved. There were no other serious adverse reactions. There was no significant difference in TESS $(p>0.05)$.

Table 6: TESS scores (mean \pm SD, $n=32$ )

\begin{tabular}{lc}
\hline Group & TESS score \\
\hline Control & $4.45 \pm 1.11$ \\
Study & $5.36 \pm 0.34$ \\
\hline
\end{tabular}

\section{DISCUSSION}

Studies have found that the pathological changes in depression are manifested in the central nervous system, and involve the central monoamine neurotransmitters. In particular, there are reductions in norepinephrine and serotonin, leading scholars to postulate the "monoamine depletion hypothesis" [8]. In addition, the influence of dysfunction in the hypothalamic-pituitary-adrenal axis, and increased glucocorticoid levels have attracted a lot of research interest [9]. With increasing social pressure, the prevalence of depression in China $(1-5 \%)$ has increased significantly over the years. Studies have shown that fluoxetine hydrochloride is a serotonin re-uptake agent that can directly block the 5-HT receptor on GABA neurons, thereby making NE neurons to exhibit a weak and indirect inhibitory excitation [10]. Therefore, studies have focused on investigating whether combination of drugs can enhance clinical effects in patients with depression.

Amitriptyline hydrochloride is a traditional tricyclic antidepressant popularly used in clinical practice. Its main function is to block the recovery of serotonin and NE neurons at the same time, thereby enhancing the transmitter concentration and synaptic transmission function in the synaptic gap. Therefore, its clinical effectiveness is high. However, amitriptyline has anticholinergic and anti-histamine effects, and is associated with many adverse reactions such as lethargy, dry mouth and loss of appetite [11]. Fluoxetine hydrochloride is a selective re-uptake drug with anti-5-hydroxytryptamine and an indirect antidepressant effect, but is absorbed orally and it is not cardiotoxic [12]. Several recent studies have shown that amitriptyline hydrochloride tablets combined with fluoxetine hydrochloride enhance the effectiveness of treatment for depression, while reducing adverse reactions [13]. In the present study, total effectiveness was markedly higher in the study group than in the control patients. However, adverse reactions were slightly higher, which are obviously related to the side effects of amitriptyline hydrochloride. Due to the small dose and mild adverse reactions, the patients could tolerate and overcome them after symptomatic treatment. Thus, the adverse reactions did not affect judgment of clinical treatment outcomes.

The clinical use of amitriptyline hydrochloride combined with fluoxetine hydrochloride on patients with depression has been reported in many studies in China and elsewhere, but there are few reports on the effect of amitriptyline hydrochloride combined with fluoxetine hydrochloride on PSQI, HAMD-17, HAMA score, as well as GABA and $5-\mathrm{HT}$ levels in these patients [13]. The PSQI is used to evaluate quality of sleep in patients with sleep problems. High PSQI scores are associated with deterioration in quality of sleep. The 17 items in the HAMD scale, the most commonly used scale for assessing depression status, reflect the severity of the disease: the higher the score, the more serious the disease. The Hamilton anxiety (HAMA) scale is mainly used for assessment of the severity of anxiety symptoms. The higher the score, the more obvious the anxiety degree.

Gamma-aminobutyric acid plays an important role in human brain cortex, thalamus and cerebellum. It inhibits central nervous system hyper-excitation and improves sleep quality. 5Hydroxytryptamine $(5-\mathrm{HT})$, an inhibitory neurotransmitter, is found at high levels in the cortex and the synapses of the brain. Functional abnormalities in 5-HT may be related to mental disorders and diseases, including migraines.

Some studies have found that concomitant changes in thyroid function during rehabilitation of emotional mental disorders play an important role [14]. Reduction in thyrotropin is likely to 
provoke depression, but it cannot be used as a specific biomarker of depression $[15,16]$. Changes in the levels of PSQI, HAMD-17, HAMA score, GABA, 5-HT and thyroid function in patients with depression reflect the severity and progression of the disease, and these are closely related to the clinical effects of treatment.

In this study, PSQI, HAMD-17 and HAMA scores of the two groups were decreased posttreatment, and the reduction was higher in the combined-treatment patients than in control patients. These results indicate that amitriptyline combined with fluoxetine significantly improves the conditions of depression patients, reduces their degree of anxiety and improves their sleep quality. The serum GABA and 5-HT were significantly higher than their levels before treatment, and the increase was higher in the study group than in the control group. After treatment, thyroid function was improved in both groups, when compared with values before treatment, but the study group showed higher improvement than the control group.

\section{Limitations of the study}

One major limitation of this study is the noninclusion of a separate amitriptyline hydrochloride control group for evaluating the effect of amitriptyline hydrochloride on patients with depression.

\section{CONCLUSION}

The combination of amitriptyline hydrochloride tablets and fluoxetine hydrochloride in the treatment of patients with depression produces beneficial clinical effects and good safety, and improves thyroid function and serum levels of GABA and 5-HT. This combination therapy reduces depression and improves sleep quality. Moreover, PSQI, HAMD-17, HAMA score, GABA and 5-HT levels are effectively adjusted, and incidence of adverse reactions are lower. Thus, the two drugs are effective, safe and reliable, and therefore may be considered for the treatment of depression.

\section{DECLARATIONS}

\section{Conflict of Interest}

No conflict of interest associated with this work.

\section{Contribution of Authors}

We declare that this work was done by the author(s) named in this article and all liabilities pertaining to claims relating to the content of this article will be borne by the authors. All authors read and approved the manuscript for publication. Yin Jie conceived and designed the study; Yin Jie, Deng Shuang, Zhan Xinjie collected and analyzed the data, while Yin Jie wrote the manuscript.

\section{REFERENCES}

1. Fu JQ, Yu QH, LU CH. Clinical study on zolpidem combined with paroxetine in treatment of depression and insomnia. Drugs Clin 2016; 31(8): 1264-1267.

2. Huang HY. Effect of fluoxetine hydrochloride combined with cognitive behavioral therapy on postpartum depression. Chin Foreign Med Res 2017; 15(31): 61-63.

3. Sinyakova NA, Kulikova EA, Englevskii NA, Kulikov AV. Effects of Fluoxetine and Potential Antidepressant 8Trifluoromethyl 1, 2, 3, 4, 5-Benzopentathiepin-6-Amine Hydrochloride (TC-2153) on Behavior of Danio rerio, Fish in the Novel Tank Test and Brain Content of Biogenic Amines and Their Metabolites. Bull Exp Biol Med 2018; 3(1): 1-4.

4. Pathan IB, Mene $H$, Bairagi S. Quality by design ( $Q b D)$ approach to formulate in situ gelling system for nose to brain delivery of Fluoxetine hydrochloride: Ex-vivo and In-vivo study. Ars Pharm 2017; 58: 107-114.

5. Chen ZP, Hou CY. An effect of Xiaoyao San plus fluoxetine hydrochloride on depression. Clin J Chin Med 2017; 9(10): 59-61.

6. World Health Organization. Declaration of Helsinki. $\mathrm{Br}$ Med J 1996; 313(7070): 1448-1449.

7. Bai JJ, Luo N, Wang SD. Influence of fluoxetine on cardiac function and quality of life in elderly chronic heart failure patients with and depression. $J$ Int Psychiatr 2017; (5): 853-856.

8. Miller $A H$, Raison $C L$. The role of inflammation in depression: from evolutionary imperative to modern treatment target. Nat Rev Immunol 2016; 16(1): 22-34.

9. Sundquist K, Frank G, Sundquist J. Urbanisation and incidence of psychosis and depression. British $J$ Psychiatr 2018; 184(4): 293-298.

10. Zhao LC, Yin XB, Sun HW. The Relationship between the Level of Depression, Life Quality and Suicide Risk in Patients with Depression. China J Health Psychol 2016; 24(7): 983-986.

11. Papich MG. Amitriptyline Hydrochloride. Saunders Handbook Vet Drugs 2016; 3: 34-35.

12. Papich MG. Fluoxetine Hydrochloride. Saunders Handbook Vet Drugs 2016; 46: 339-341.

13. Chen JJ. To explore the different clinical effects of duloxetine and fluoxetine in treating first-episode depression. Heilongjiang Med J 2017; 30(6): 1274-1276.

14. Li GQ, Zhou WD, He Y, Nie X, Li GX. The research about changes of thyroid function in patients with depression. Int J Lab Med 2017; 38(18): 2556-2558.

15. Yang $Z Y, Y u T$. Progress in the functional regulation of norepinephrine on neurons, glial cells and microglial 
Jie et al

cells and its mechanism. Shandong Med J 2017; 57(11):

99-102.
16. Liu FK, Li LH, Fan CH. Thyroid function in first-episode depressive patients. Guangdong Med J 2013; 34(3): 371-374. 